\title{
Atenção à saúde da população em uma Unidade Escola: relato de experiência
}

\author{
Population health care in a School Unit: experience report
}

Atención de salud poblacional en una Unidad Escuela: relato de experiencia

Denise Maria Woranovicz Carvalho ${ }^{1}$, Sandra Mara Woranovicz Barreira ${ }^{1 *}$.

\begin{abstract}
RESUMO
Objetivo: Descrever as atividades do projeto que visa à saúde da população mediante integração ensinocomunidade em uma Unidade Escola de promoção de saúde de uma universidade pública no sul do Brasil. Relato de experiência: Diante de desafios relacionados à promoção de saúde, surgiu a necessidade de maior conscientização acerca da prevenção para alcançar uma sociedade com hábitos de vida saudáveis. A Unidade Escola de promoção de saúde é um espaço que, entre outras atividades relacionadas à saúde, oferta palestras presenciais e online que educam, orientam e impactam inúmeros participantes da comunidade interna e externa à universidade. Considerações finais: A integração ensino-comunidade tem trazido grande benefício por oferecer atenção especial às pessoas que assistem as palestras. A transformação é evidente com a participação de inúmeras pessoas nas palestras oferecidas. A formação obtida por estudantes bolsistas e voluntários é diferenciada e torna tais estudantes mais preparados. Este projeto acrescenta benefícios excepcionais para a toda a comunidade atendida.
\end{abstract}

Palavras-chave: Promoção de saúde, Palestras, Comunidade.

\begin{abstract}
Objective: To describe the project activities that aims the population's health by teaching-community integration in a health promotion School Unit of a public university in southern Brazil. Experience report: Faced with challenges related to health promotion, there was a need for greater awareness of prevention in order to achieve a society with healthy lifestyle habits. The health promotion School Unit is a place that, among other health-related activities, offers presential and online lectures that educate, guide and impact countless participants from the community inside and outside the university. Final considerations: The teachingcommunity integration has brought great benefits by offering special attention to people who attend the lectures. The transformation is evident with the participation of countless people in the lectures offered. The training obtained by scholarship students and volunteer students are differentiated and makes such students more prepared. This project adds exceptional benefits to the entire community.
\end{abstract}

Keywords: Health promotion, Lectures, Community.

\section{RESUMEN}

Objetivo: Describir las actividades del proyecto que tiene como objetivo la salud de la población a través de la integración docente-comunidad en una Unidad Escuela de promoción de la salud de una universidad pública del sur de Brasil. Informe de experiencia: Ante los desafíos relacionados con la promoción de la salud, se necesitaba una mayor conciencia de la prevención para lograr una sociedad con hábitos de vida saludables. La Unidad Escuela de promoción de la salud es un sitio que, entre otras actividades relacionadas con la salud, ofrece conferencias presenciales y online que educan, orientan e impactan innumerables participantes de la comunidad dentro y fuera de la universidad. Consideraciones finales: La integración docente-comunidad ha traído grandes beneficios al ofrecer una atención especial a las personas que asisten a las conferencias. La transformación es evidente con la participación de innumerables personas en las conferencias ofrecidas. La formación que obtienen los becarios y voluntarios es diferenciada y prepara más a los estudiantes. Este proyecto agrega beneficios excepcionales a toda la comunidad.

Palabras clave: Promoción de la salud, Conferencias, Comunidad.

1 Universidade Federal do Paraná (UFPR), Curitiba - PR. *E-mail: sandra@ufpr.br 


\section{INTRODUÇÃO}

Depois que terminou a Segunda Guerra Mundial, foi fundada a Organização Mundial da Saúde (OMS), que criou uma definição de saúde visando a ampliar a concepção de ausência de doença e incluir bem-estar físico, psíquico e social. As políticas promovidas originaram melhoria das condições de vida e trabalho, o que aumentou a expectativa de vida (MINAYO MCS, 2019). Alternativas à definição da OMS culminaram em novas definições (SILVA MJS, et al., 2019).

Na 1a Conferência de Promoção da Saúde da Fiocruz, em 2019, foram destacados marcos da promoção de saúde: a Conferência de Alma-Ata (fundamental na história da saúde), a Carta de Ottawa (primeira Conferência Internacional sobre Promoção à Saúde) e a Conferência de Astana, com foco na implementação dos 17 Objetivos do Desenvolvimento Sustentável (ODS); cumpre entender, na opinião de Paulo Buss, a promoção de saúde com foco no indivíduo, na comunicação em saúde, e olhando a saúde como um todo (DIAS J, 2019).

A ligação entre condições ambientais e desenvolvimento econômico e social é crucial no processo saúdedoença e, porquanto a Constituição Federal Brasileira de 1988 institui a saúde como direito de todos, cumpre alinhar-se ao teor da Declaração de Alma-Ata, de 1978; destarte, governos formularam estratégias, planos e políticas nacionais para enfrentar determinantes ambientais e sociais da saúde (GIOVANELLA L, et al., 2019).

Saúde como "não doença" foi reassegurada por muito tempo e ainda existe assistência focada na doença e na abordagem biomédica (RIOS DRS, et al., 2019; SILVEIRA JLGC, et al., 2020; SOUZA CL, et al., 2020). Uma alternativa é o cuidado integral, que considera o contexto biopsicossocial como nova forma de cuidar (SILVEIRA JLGC, et al., 2020). Concernente com a Constituição Federativa, transformações voltadas à promoção da saúde vêm sendo propostas, o que implica mudanças no modelo de atenção com foco na doença e em aspectos biológicos (NALOM DMF, et al., 2019).

A prevenção de doenças tem a finalidade de evitar que ocorra adoecimento. A partir da observação de fatores biológicos, sociais, sanitários e emocionais pode-se combater causas e prevenir doenças (MOLL MF, et al., 2019). Estudos corroboram tal afirmação: Silva GSM, et al. (2021) conduziram pesquisa que avaliou o efeito de um programa de intervenção de atividade física, educação e promoção de saúde e concluíram que houve mudança no comportamento do usuário sobre seu estilo de vida e melhoria na qualidade de vida.

Existe também o estabelecimento da promoção de saúde por meio de saberes técnicos: trata-se da educação em saúde com o intuito de promover mudanças no estilo de vida da população (MOLL MF, et al., 2019). Temáticas relacionadas à saúde vêm sendo objeto de trabalho e tais esforços refletem formas de compreender conceitos de educação e saúde (MARTINS I, 2019).

É necessário que o Brasil mude da assistência centrada na doença para um conceito de atenção à saúde que considere o contexto social e a integralidade das ações para que, por meio da promoção de saúde, expresse a qualidade de vida da população (SCHIOCHET GF, et al., 2020). A promoção de saúde vai além da assistência médico-curativa (BRANCO PR e ANDRADE EA, 2020). Todo indivíduo deve poder alcançar seu estado de saúde ideal (GALVÃO ALM, et al., 2021).

Para que a população adquirira conhecimento e seja agente da mudança de hábitos, há campanhas para a propagar informações sobre saúde por meio de palestras, cartazes e folders. Ferramentas tecnológicas estão disponíveis e são uma forma de propagação dessa educação para a população, na forma de textos ou cartazes digitalizados (SALES A, et al., 2020).

O objetivo deste relato de experiência foi detalhar as atividades do projeto de extensão universitária que visa à saúde da população mediante integração ensino-comunidade em uma Unidade Escola de promoção de saúde de uma universidade pública no sul do Brasil. O projeto foi desenvolvido visando à realização de ciclos de palestras aos servidores, estudantes e comunidade externa à universidade, com a finalidade educativa de promoção de saúde, propagando autocuidado e mudanças de hábitos físicos e alimentares, para melhorar a qualidade de vida. 


\section{RELATO DE EXPERIÊNCIA}

Este relato tem base na prática vivenciada, ao longo de cinco anos, num projeto de extensão. As atividades de atenção à saúde da população desenvolvidas no projeto fazem parte da Unidade Escola de promoção de saúde, onde ocorrem ações de prevenção da saúde e são ofertados, de forma gratuita aos usuários, os Programas de Hipertensão Arterial, Dislipidemias e Diabetes e Nutrição. Neste espaço ocorrem ações de extensão universitária que valorizam a função social da universidade.

A oferta de um ciclo contínuo de palestras na área da saúde também faz parte das ações da Unidade Escola. A aprovação do projeto pelo Comitê Assessor da universidade ocorreu em 2016. De caráter humanitário e social, busca a educação na promoção da saúde atendendo os anseios da comunidade universitária. Servidores, estudantes e comunidade externa à universidade assistem um ciclo de palestras de cunho educativo e sanitário e há ganhos acadêmicos na inserção e imersão dos estudantes no desenvolvimento de competências para um trabalho de qualidade profissional.

Conta com palestrantes do meio acadêmico e profissional. Participam do projeto: coordenadores, estudantes de graduação (extensionistas do projeto, bolsistas e voluntários) e os inscritos que assistem as palestras, ministradas por docentes e discentes dos cursos de graduação e pós-graduação, alunos egressos e, eventualmente, por profissionais externos.

As palestras são apresentadas em linguagem de fácil compreensão; são gratuitas, quinzenais, com duração aproximada de uma hora e os palestrantes e participantes recebem certificado de participação. $O$ horário das palestras busca facilitar a participação de todos e, ao término, os participantes são convidados a preencher um questionário (anônimo) para avaliar o conteúdo ministrado. Os participantes têm um espaço para registrar necessidades de futuros temas que eles desejam ouvir e, após a palestra, podem permanecer no local para conversar com o palestrante, o que reforça a interação dialógica no projeto.

Além das palestras, o projeto promove a divulgação de textos relevantes sobre saúde, visando a manter a população sempre atenta a assuntos úteis que promovem saúde e qualidade de vida. Tudo é decidido em reuniões da equipe.

A seguir são detalhadas as três atividades principais do projeto: a) palestras presenciais, b) palestras online e c) utilização das redes sociais para postagem de matérias relacionadas a datas que comemoram saúde e qualidade de vida.

\section{Palestras presenciais}

As palestras presenciais foram realizadas no auditório da Unidade Escola de promoção de saúde. Na Unidade Escola há salas de atendimento médico, fitness e reuniões; há também um auditório com capacidade para 60 pessoas. No auditório, entre 2016 e 2019, mais de 2500 pessoas foram impactadas: foram ministradas 76 palestras de atenção à saúde, num cronograma adaptado às doenças mais prevalentes (Quadro 1).

Quadro 1 - Principais temas das palestras ministradas entre 2016 e 2019.

\begin{tabular}{|c|c|c|c|}
\hline Ano & Número de palestras & Número de Pessoas & Principais temas \\
\hline 2016 & 11 & 300 & $\begin{array}{l}\text { Hipertensão arterial, saúde mental, câncer } \\
\text { de mama, saúde masculina, estética facial e } \\
\text { qualidade de vida }\end{array}$ \\
\hline 2017 & 21 & 650 & $\begin{array}{l}\text { Depressão, diabetes, hepatite, magnésio na } \\
\text { saúde, gorduras na saúde, Alzheimer }\end{array}$ \\
\hline 2018 & 24 & 1000 & $\begin{array}{l}\text { Violência contra as mulheres, estresse, } \\
\text { obesidade e atividade física, autismo, } \\
\text { satisfação de vida na aposentadoria, luto na } \\
\text { infância e na adolescência }\end{array}$ \\
\hline 2019 & 20 & 610 & $\begin{array}{l}\text { Saúde da mulher na menopausa, } \\
\text { suplementos alimentares, abuso sexual } \\
\text { infantil, ansiedade no dia a dia, } \\
\text { esquizofrenia }\end{array}$ \\
\hline
\end{tabular}

Fonte: Carvalho DMW e Barreira SMW, 2021. 


\section{Palestras online}

A pandemia da COVID-19 trouxe uma nova realidade, e a Unidade Escola precisou se adaptar: no ano de 2020 foi necessário planejar ações que permitiriam que o projeto assumisse um caráter virtual, tornando necessário buscar aprendizado acerca das plataformas de transmissão, executar a reformulação do projeto para operação de forma online, planejar e dimensionar o número de palestras mensais.

Em 2020 foi desenvolvido um vídeo que contou a história da Unidade Escola desde a sua criação até o final de 2019. Esse vídeo foi enviado por e-mail às pessoas que tiveram contato com a Unidade Escola. Foi a mensagem de final de ano da Unidade Escola para toda a comunidade.

Em 2021 o projeto foi aprovado para atuação em caráter virtual. A plataforma escolhida foi o StreamYard com transmissão pelo YouTube. Até o presente momento já foram ministradas palestras de forma online (Fitoterápicos, Esquizofrenia, Diabetes Gestacional, Lúpus Eritematoso Sistêmico) e outras ainda ocorrerão (Violência Contra a Mulher, Suicídio, etc.).

As redes sociais têm papel preponderante na divulgação das palestras, pois permitem proximidade e interação do público com a Unidade Escola. Para divulgar as palestras, optou-se pela comunicação via email, Facebook e Instagram, visando a aumentar a visibilidade e promover compartilhamentos e interação com o público.

\section{Postagens mensais}

O calendário de saúde do Ministério da Saúde é utilizado como referência para várias postagens mensais. São postagens curtas, em linguagem acessível, disponibilizadas no Facebook e no Instagram, e fazem menção a datas importantes na área da saúde (por exemplo, Dia Mundial da Saúde Ocular, Dia Mundial da Hepatite Viral, Semana de Amamentação, Dia do Cardiologista).

\section{DISCUSSÃO}

A respeito das atividades presenciais antes da pandemia da COVID-19, a integração ensino-comunidade trouxe grande benefício por oferecer atenção especial às pessoas que assistiram às palestras no auditório. Oferecer palestras gratuitas permitiu que os servidores tivessem orientações, aconselhamento, conhecimentos sobre patologias, o que propicia qualidade de vida. Para Santos PR, et al. (2019), a ministração de palestras para as comunidades interna e externa ao ambiente universitário contribui para o fortalecimento do conceito de extensão universitária.

As palestras online foram bem aceitas pela comunidade. De fato, Nogueira PG, et al. (2021) afirmam que, diante do cenário de pandemia, pessoas, instituições e serviços precisaram se reinventar e tiveram suas rotinas remodeladas. $\mathrm{O}$ isolamento social dificulta ações relacionadas à saúde; o Brasil precisa de uma agenda de serviços adequados e específicos (MINAYO MCS e FREIRE NP, 2020; MINAYO MCS, 2019). A Unidade Escola tem procurado manter suas ações mesmo neste período difícil, e a utilização da internet tem propiciado tal continuidade. A internet é uma interface necessária em comunicação e saúde e um desafio para a área da educação na saúde (PINTO PA, 2019; FRANÇA T, et al., 2019).

As postagens mensais alcançam toda a comunidade; por meio de textos curtos e de leitura rápida, conteúdos são publicados e compartilhados. Os meios digitais e as redes sociais estão transformando a promoção de saúde. As mídias digitais exercem papel importante na disseminação em saúde: ajudam na busca de informações, facilitam o acesso aos conteúdos e são um espaço para interação e compartilhamento de experiências (LIMA CP, et al., 2021). São ações de promoção de saúde no contexto da tecnossocialidade, ou seja, formas de interações sociais facilitadas pelas novas tecnologias (ALVES TF, et al., 2021).

Redes sociais integram pessoas, e a utilização do Instagram tem sido eficiente. O Instagram, uma mídia social de fácil utilização, promove a comunicação entre os usuários por meio de compartilhamento de vídeos e imagens (MELO MEFA, et al., 2021). Utilizar o Instagram na comunidade acadêmica para promoção de valorização e cuidado é útil e efetivo (SILVA KR, et al., 2021). O Facebook também tem trazido resultados adequados. Profissionais e instituições da área da saúde usam o Facebook, uma das mídias digitais mais utilizadas no mundo, para promoção da saúde (SANTOS FF e PINTO-E-SILVA MEM, 2021). 
A literatura reconhece a importância de tais ferramentas, fato suportado pelo volume de tecnologias móveis de acesso à internet, como tablets e celulares, e Facebook, Instagram e YouTube são reconhecidos internacionalmente como mídias sociais úteis para disseminação de informações de saúde (FRANÇA T, et al., 2019).

O princípio ensino, pesquisa e extensão é respeitado, pois a comunidade usufrui de informações pertinentes à tríade. No ensino, os discentes que participam na ministração das palestras aprendem a preparar uma palestra e transmitir informações. O preparo de palestras proporciona a descoberta e o interesse por assuntos significativos para o estudante, o que promove troca de conhecimentos com diversos públicos, além de questões que surgem durante as palestras e ampliam o leque de aprendizado (SANTOS PR, et al., 2019).

Estas atividades tiveram mais um desafio no modo online: conhecer o ambiente virtual e interagir com os ouvintes de forma remota, via plataforma. A necessidade de distanciamento social trouxe mudanças no comportamento e no dia a dia das pessoas em diversos países (LIMA CP, et al., 2021).

Na pesquisa, os palestrantes apresentam informações de seus trabalhos e de outras fontes bibliográficas. Dados dos questionários respondidos são base para pesquisas futuras e temas para palestras. A extensão é uma estratégia fundamental para a formação acadêmica e profissional, pois aproxima os estudantes das necessidades da população, o que leva os acadêmicos a repensarem seus saberes e fazeres quando confrontados com os desafios que emergem de realidades complexas (RIOS DRS, et al., 2019).

$\mathrm{Na}$ extensão, as atividades atingem o objetivo, pois inúmeras pessoas participam, ouvem e sanam suas dúvidas nos temas abordados. A pesquisa de Brayde DHS, et al. (2019) enfatizou a integração ensino-serviço como estratégia de ensino-aprendizagem, porquanto aproxima o discente da realidade da saúde. Os achados de Franco SC, et al. (2019) corroboram tal assertiva, pois na análise da pesquisa de campo, as avaliações dos respondentes foram positivas com relação à integração ensino-serviço no tocante à inserção dos estudantes na atenção à saúde.

A formação de extensionistas prepara para o trabalho. Uma das tarefas é realizar pesquisas relacionadas à saúde e publicar nas mídias sociais em linguagem de fácil entendimento. Para Sales A, et al. (2020), materiais educativos impressos ou digitais têm concisão no texto escrito, impessoalidade, cores e figuras, em consonância com o tema que se pretende implementar, levando em conta as circunstâncias e o público-alvo.

A necessidade de operar plataformas para divulgação das palestras, bem como de conhecer a realidade do ambiente virtual de aprendizagem, faz com que extensionistas sejam capazes de interagirem com colegas e exercitarem o trabalho em equipe. No antigo modelo de cuidado em saúde, cada profissional trabalha sozinho, mas no mundo todo observa-se crescimento das práticas interprofissionais (SOUZA MA, et al., 2021).

A interdisciplinaridade está presente, pois profissionais e estudantes de diferentes áreas colaboram. A interação dialógica é atendida em reuniões com a equipe executora do projeto e em diálogos construtores entre os palestrantes e participantes. Programas e atividades de extensão que têm base na interdisciplinaridade e na interprofissionalidade propiciam trocas de experiências entre os acadêmicos e a população (RIOS DRS, et al., 2019).

É emocionante verificar o desabafo, o sorriso e o agradecimento de uma pessoa da plateia. Para o/a palestrante, nada mais gratificante. Em relato de experiência, Patrício RSO, et al. (2020) apresentam ações de promoção de saúde e qualidade de vida realizadas com mulheres e apontam a necessidade que elas têm de falar e de serem ouvidas. Silveira JLGC, et al. (2020) citam um estudo onde o preparo dos profissionais de saúde conta com o auxílio de organizações comunitárias e de pacientes que detêm conhecimentos, e para serem socialmente responsivas, as escolas profissionais e as universidades contam com parcerias com a comunidade.

Este projeto constitui um esforço da universidade para o desenvolvimento social, econômico e cultural. A integração ensino-comunidade contribui para que a universidade reflita o seu papel na sociedade. Num mundo tão conectado, é mister estimular a população a se tornar mais consciente mediante estratégias interdisciplinares de promoção da saúde (SOUZA-JUNIOR JR, et al., 2020). 
A execução deste projeto de atenção à saúde demonstra que a extensão é um valioso instrumento de transformação social. Orientar a população e oportunizar espaços onde os docentes e discentes possam interagir de forma dialógica entre si e com a comunidade traz ganhos excepcionais para a comunidade acadêmica e para a comunidade atendida, estreitando os laços entre a universidade, servidores, familiares e parentes de docentes e discentes.

\section{REFERÊNCIAS}

1. ALVES TF, et al. Promoção da saúde no contexto da tecnossocialidade: Revisão integrativa da literatura. Revista Nursing, 2021; 24(276): 5686-5692.

2. BRANCO PR, ANDRADE EA. Efetividade do treinamento em habilidades sociais na qualidade de vida de trabalhadores: Uma estratégia de promoção da saúde. Revista Eletrônica Acervo Saúde, 2020; 12(10): e4038.

3. BRAYDE DHS, et al. Integração ensino-serviço: As experiências e fragilidades na atenção básica. Revista Eletrônica Acervo Saúde, 2019; Vol.Sup.26: e757.

4. DIAS J. Palestra na Fiocruz traça histórico da promoção à saúde. 2019. Disponível em: https://agencia.fiocruz.br/palestra-na-fiocruz-traca-historico-da-promocao-saude. Acesso em: 16 de julho de 2021.

5. FRANÇA T, et al., As mídias e as plataformas digitais no campo da educação permanente em saúde: Debates e propostas. Saúde Debate (Rio de janeiro), 2019; 43(n. especial 1): 106-115.

6. FRANCO SC, et al. Análises pelos discentes de uma escola médica das atividades de integração ensino-serviço na graduação. Revista Eletrônica Acervo Saúde, 2019; Vol.Sup.33: e921.

7. GALVÃ̃ ALM, et al. Determinantes estruturais da saúde, raça, gênero e classe social: Uma revisão de escopo. Saúde e Sociedade (São Paulo), 2021; 30(2): e200743.

8. GIOVANELLA L, et al. De Alma-Ata a Astana. Atenção primária à saúde e sistemas universais de saúde: Compromisso indissociável e direito humano fundamental. Cadernos de Saúde Pública, 2019; 35(3): e00012219.

9. LIMA CP, et al. Estratégias de comunicação em saúde mental em tempos de pandemia. RSPP Revista de Saúde Pública do Paraná, 2021; 4(1):119-132.

10. MARTINS I. Educação em ciências e educação em saúde: Breves apontamentos sobre histórias, práticas e possibilidades de articulação. Ciência \& Educação (Bauru), 2019; 25(2): 269-275.

11. MELO MEFA, et al. Tempos de pandemia: Educação em saúde via redes sociais. Revista de Extensão da UPE, 2021; 6(1): $38-48$

12. MINAYO MCS. O imperativo de cuidar da pessoa idosa dependente. Ciência \& Saúde Coletiva, 2019; 24(1): $247-252$.

13. MINAYO MCS, FREIRE NP. Pandemia exacerba desigualdades na saúde. Ciência \& Saúde Coletiva, 2020; 25(9): 3555-3556.

14. MOLL MF, et al. O enfermeiro na saúde da família e a promoção de saúde e prevenção de doenças. Enfermagem em Foco, 2019; 10(3):134-140.

15. NALOM DMF, et al. Ensino em saúde: Aprendizagem a partir da prática profissional. Ciência \& Saúde Coletiva, 2019; 24(5): 1699-1708.

16. NOGUEIRA PG, et al. O uso de plataformas digitais como auxílio no processo ensino e aprendizagem de ciências: Um relato de experiência. RECHRevista Ensino de Ciências e Humanidades, 2021; 2: 211-224.

17. PATRÍCIO RSO, et al. Ações de enfermagem na promoção da saúde e qualidade de vida de mulheres no climatério. Revista Eletrônica Acervo Enfermagem, 2020; 4: e4782.

18. PINTO PA. Marketing social e digital do Ministério da Saúde no Instagram: Estudo de caso sobre aleitamento materno. Reciis Revista Eletrônica de Comunicação, Informação e Inovação em Saúde, 2019; 13(4):817-30.

19. RIOS DRS, et al. Diálogos interprofissionais e interdisciplinares na prática extensionista: O caminho paraa inserção do conceito ampliado de saúde na formação acadêmica. Interface (Botucatu), 2019; 23: e180080.

20. SALES A, et al. Análise de materiais educativos utilizados nas campanhas de saúde coletiva sobre o tabagismo. Revista de Ensino, Educação e Ciências Humanas, 2020; 21(2): 141-146.

21. SANTOS FF, PINTO-E-SILVA MEM. Ciclo do marketing digital como estratégia para otimizar a comunicação de informações ligadas à alimentação e nutrição, na mídia social Facebook. Demetra Alimentação, Nutrição \& Saúde, 2021; 16: e48812.

22. SANTOS PR, et al. A utilização de palestras como ferramentas para o ensino da anatomia e integração com a comunidade. Brazilian Journal of Development (Curitiba), 2019; 5(12): 28750-28755.

23. SCHIOCHET GF, et al. Relato de experiência da formação de um grupo de promoção de saúde na estratégia de saúde da família. Pensar Acadêmico (Manhuaçu), 2020; 18(3): 591-606.

24. SILVA GSM, et al. Efeitos de um programa de intervenção de atividade física, educação e promoção de saúde com idosos hipertensos usuários do Sistema Único de Saúde. Revista Eletrônica Acervo Saúde, 2021; 13(4): e6926.

25. SILVA KR, et al. Cuidar de quem cuida: A página do Instagram como tecnologia adicional para promoção da saúde mental dos trabalhadores de serviços de saúde. Brazilian Journal of Development (Curitiba), 2021; 7(6): 56679-56690.

26. SILVA MJS, et al. O conceito de saúde na saúde coletiva: Contribuições a partir da crítica social e histórica da produção científica. PhysisRevista de Saúde Coletiva (Rio de Janeiro), 2019; 29(1): e290102.

27. SILVEIRA JLGC, et al. Percepções da integração ensino-serviço-comunidade: Contribuições para a formação e o cuidado integral em saúde. Interface (Botucatu), 2020; 24: e190499.

28. SOUZA CL, et al. Ambiente e promoção da saúde: Vivências no território adscrito na perspectiva dos usuários. Revista Eletrônica Acervo Saúde, 2020; 12(12): e5059.

29. SOUZA MA, et al. Atuação interprofissional vivenciada no Programa de Educação pelo Trabalho pela Saúde: Um relato de experiência. Revista Eletrônica Acervo Saúde, 2021; 13(6): e6945.

30. SOUZA-JUNIOR JR, et al. COVID-19 e a promoção da saúde em tempos de pandemia. Revista Eletrônica Acervo Saúde, 2020; Vol.Esp.46: e3837. 